\title{
USING MUSIC ACTIVITIES TO ENHANCE THE LISTENING SKILLS AND LANGUAGE SKILLS OF GRADE 1, ENGLISH FIRST ADDITIONAL LANGUAGE LEARNERS
}

Anna J Hugo and Catharina A Horn

University of South Africa

Music activities can be used to develop and enhance young learners' listening abilities. Listening is a language skill which is a prerequisite for the development of other language skills and especially for the development of a person's speaking abilities. It is also a prerequisite for the development of a person's language abilities in a second language. In a research project involving a group of 70 English first additional language learners, two Grade 1 classes were selected. One class was the experimental group and the other class was the comparison group. Over a period of six months the experimental group received planned music activities daily. When the two groups were retested after six months, significant differences in the means between the experimental and the control groups were found. The experimental group significantly improved their listening skills in English as a second language (ESL). This has implications for teaching ESL learners in the Foundation Phase.

\section{INTRODUCTION}

This article is an attempt to show that if teachers in Early Childhood Education are aware of the value of music programmes and if they plan music programmes for their young custodians well, all learners in their classrooms can benefit. Young ESL learners could specifically benefit from such programmes because they will help to develop their listening skills, which are important when learning a second language. The ESL learners' language skills in the second language could also be enhanced.

\section{THE LANGUAGE OF INSTRUCTION IN SOUTH AFRICAN SCHOOLS}

The language of instruction for young learners entering the formal school situation for the first time in Grade One 1 varies. Many learners are taught in their home language, learning English as a second language from Grade 2, and then they are taught in English from Grade 4 onwards. This is in line with the language policies of the National Department of Education (Parliamentary Monitoring Group, 2006:2). The right to choose the language of instruction is vested in the individual and a minor learner's parents exercise the right to choose the

\footnotetext{
${ }^{1}$ It is acknowledged that the South African Department of Basic Education uses the term English as first additional language. But for the purposes of this article the term English as a second language will be used.
} 
language of learning and teaching (Department of Education, 1997:2). For various reasons, the majority of South Africans prefer English and not their home language as the language of learning and teaching (De Wet, 2002:119). Some young children attend preschools where English is spoken, but the majority of these children enter Grade 1 in schools where English is used as the medium of instruction, without the children having had any training in or exposure to English as a second language. Many of these young learners thus lack the necessary proficiency in English to function effectively in a learning environment.

\section{English as a second language used as the medium of instruction}

It is a reality in South Africa that schools increasingly have to deal with diverse cultures and learners from many different backgrounds. However, it is the opinion of the authors that all children have a right to education and their need to make academic progress at school should be addressed in the classroom. The research project described in this article is an attempt to address the need of young learners with regard to English as a second language (ESL) used as the medium of instruction in their classrooms.

Many children in the world, including children in South Africa, are taught through the medium of English, which is their second language. This is a great challenge to these children. Sometimes it results in young children trying to communicate using their home language when the other children and staff members use English (a communication strategy known as bilingual discourse). It could also result in the ESL speakers entering a silent period, during which they stop communicating verbally, or a so-called rejection period during which the children become socially isolated and reluctant to interact with other children or adults (Gordon, 2007:57-58). A young Korean-American remembers his silent period in the following way: 'I had spent kindergarten in almost complete silence, hearing only the high nasality of my teacher and comprehending little but the cranky wails and cries of my classmates' (Gordon, 2007:58).

English is used as the medium of instruction in most of the Anglophone countries in Africa, and thus, for many children, instruction in their mother tongue is still denied. At an ADEA biennial meeting in Gabon, a report on the language of learning and teaching in all African countries was discussed (Alidou, Boly, Brock-Utne, Diallo, Heugh \& Wolff, 2006). It becomes clear from this report that in many classrooms in Africa where children are not taught in their mother tongue, it is usually only the teacher who speaks. Often the children keep quiet because they do not understand what the teacher is talking about. There are other consequences as well, as one of the six authors of the report, Alidou, states: 'Because children do not understand the language of teaching, the teachers are forced to use traditional teaching techniques such as chorus teaching, repetition, memorization, recall, code-switching and safe talk. In this context authentic teaching cannot take place.' (Alidou et al., 2006:15)

In South Africa, the majority of learners who study through the medium of English as their second or even third language find themselves in an 'immersion' situation. One kind of immersion is to be found in rural or township schools and the other in suburban so-called exModel C schools. Many young learners find themselves immersed in a second or third language as the language of instruction from the very outset of their schooling. These learners' home languages are accorded very little or no value inside and even outside the 
school, and thus they seldom acquire competence in their home language (Scheepers, 2006:2$3)$.

According to a research report on the language factor in education in Africa, it would be to the benefit of learners be educated in their home language for the first six years of school (Source, year:page). Under optimal conditions, it takes six to eight years to learn a second language sufficiently well to use it as the medium of instruction. This may result in learners developing language barriers (Alidou et al., 2006:15)

However, in this article, we do not attempt to address the advantages and disadvantages of using second-language English as the language of instruction but depart from the premise that, for many young learners in South Africa, having English (their second or first additional language) as the language of instruction often results in unsatisfactory progress at school. Based on an assessment study of Grade 6 learners done by the Western Cape Department of Education, Fleisch (2008:100) states:

The report concludes that while having English as one's home language does not guarantee academic success, it strongly improves one's chances. For those whose home language was different from that of the test, i.e. all isiXhosa first-language speakers, language is a major disadvantage as revealed by the shocking statistic that only 1, 6 per cent of isiXhosa home-language speakers were found to be performing at official grade level.

\section{Listening as an important language skill}

The ability to hear is not the same as the ability to listen. Although most people are born with the ability to hear, listening is a skill that must be learned. Traditionally, listening is regarded as one of the four language skills and an important prerequisite for language to develop under normal circumstances. As a young person's language develops, the abilities to listen with understanding and to speak develop together. Listening is at the very root of all human communication, both verbal and nonverbal. According to research by Madaule (2001:10) on verbal communication, listening is so crucial to the acquisition of speech and language that defective listening can lead to impaired learning.

Young learners have to use active listening to add to their understanding of and feelings about what they experience from sounds in the environment. It is therefore important that listening skills are developed in both the first and additional languages (Wessels \& Van den Berg, 1998:115). Good listening skills should be in place right from the outset, especially when a second language is learned. Learners have to listen attentively and remember the sounds of the new language, to be able to pronounce the words correctly. This means that when the new sounds are not clear or understood, the learners have to replace these sounds with equivalent sounds from their home language. New sounds are often a problem and that is why, for example, 'that' is pronounced 'zat', 'dat' or 'vat' by second-language speakers of English (Krouse, 1988:14).

The important issue of understanding should be kept in mind: although listening is a receptive skill, it is by no means a passive act because it is an act of constructing meaning. In order to understand a conversation or an oral presentation, listeners draw on their store of background knowledge and their expectations of the message to be conveyed. Teachers know that 
listening skills have to be taught: one cannot assume that the skill develops by itself (DíazRico, 2008:200-202).

For instance, the total physical response (TPR) method that is often used to teach a new or second language to young learners relies on the assumption that learners have good listening abilities. The total physical response method was developed by James Asher to aid the learning of second languages. The method relies on the idea that when a second language is learnt, the language is internalised through a process of code breaking. The process allows for a period of listening and developing an understanding before speaking the second language (Hugo, 2013:47). When the TPR method is used, the young learners are required to listen to an instruction given by a teacher, to observe while the teachers carries out the instruction and then to react and demonstrate that they understand by carrying out the instruction themselves. Learners are only required to speak when they are ready (Wessels \& Van den Berg, 1998:68).

In this article, we focus on listening skills because listening is a prerequisite for language development that includes the acquisition and development of a second language. Welldeveloped auditory perceptual abilities such as auditory discrimination and auditory sequencing lie at the heart of listening with understanding. As indicated later in this article, this is where music can play a vital role in developing young learners' listening skills as well as their auditory perceptual abilities.

\section{Music in the foundation phase classroom}

Over the centuries, music has been used for many types of activities. In Biblical times, music was not only used for praise but also for enjoyment and to relieve stress. Most children love music in one form or another and for this reason music is often used to facilitate language learning activities in schools. Music can be used to enhance speech and language skills such as auditory attention, perception and memory. Songs can be used to improve articulation, auditory awareness, memory and sound awareness (Kouri \& Telander, 2008:329, 331). Concerning English as a second language, Merdinger and Rosenfeld (1984:iv) state that 'Music is an important part of any culture. Even an unfamiliar song may be welcomed by an ESL student for whom music is a natural and familiar mode of expression.'

Although music can be practiced and experienced in a number of ways, such as by singing, listening, moving, dancing or performing instrumental improvisations, the person, as a whole, is always involved (Hallam, 2001:61). Music also has therapeutic value and this applies to the teaching of learners with barriers to learning. In schools, music can be used to promote social interaction, to motivate learners, to stabilise them emotionally and to help them work through possible perceptual, motor or learning problems (Van Deventer, 1998:4, 18, 22).

Music activities enhance whole-brain learning because speech, movement, rhythm and melody activate both the right and the left hemispheres of the brain. It has been documented that effective learning takes place when the whole brain is involved in the learning process (Eloff \& Ebersöhn, 2004:149-151). When children learn music, they learn a new set of skills. These will help to enhance their overall abilities. When children listen to music they engage in thinking activities which enhance their abilities to express themselves in their home language or second language (Salmon, 2010:939).

Kraus and Chandrasekaran (2010:599) report that children who underwent music training showed enhanced brain responses to subtle pitch changes - something that occurs when a 
second language is learned. They also observe that 15 months of music training indices improved auditory and motor skills in a group of children.

\section{THE RESEARCH DESIGN AND THEORETICAL UNDERPINNING}

The aim of this research project was to investigate how music could be used to improve the listening skills, and eventually the language skills, of ESL learners in Grade 1. Listening is the first-language skill that all individuals need to develop their language abilities. The researchers planned this research to emphasise how a well-planned music programme could enhance learners' listening skills to help them gain a better understanding of English as their second language - the language in which they learn and are taught. If the first-language skill (listening) is developed, it should enhance the other language skills: speaking, reading and writing. This could improve the learners' understanding of English and consequently aid their learning and studying in English as their second language, as well.

This research project entailed the conducting of quantitative research and the use of a basic pre-test-post-test experimental design. In this type of design, an experimental group is exposed to a treatment or intervention, while the control group does not receive the treatment. All the conditions are the same for both experimental and control groups (Dimitrov \& Rumrill, 2003:159-160). Thus, for this research, an experimental group as well as a control or comparison group were used. Both the experimental group and the comparison group received a pre-test and a post-test at the same time, but the comparison group did not receive the 'treatment' (De Vos, Strydom, Fouché \& Delport, 2005:140).

The research contained some of the elements of a positivist approach, as set out by Herrington and Oliver (2000:225-45). The elements in this research are, for instance, the provision of authentic contexts to the way in which knowledge is used in real life and of authentic activities. The positivistic paradigm is characterised by a view of reality as being independent of the knower. Objective reality exists but it can only be known by objective means. Reality is inherently ordered, and the main aim of positivism is to control and predict human and natural phenomena (Peca, 2000:1-2). Nevertheless, we, the researchers, also aimed to use the logical facts obtained from the research and apply it practically to help young learners to master the language of learning and teaching. Thus, pragmatism eventually formed part of the research project.

\section{THE RESEARCH AND DISCUSSION}

In our investigation, two groups of Grade 1 learners were used: an experimental group from one class and the control group from another. Data were collected by means of simultaneously conducted pre-tests and post-tests. The learners came from an English primary peri-urban school, where the medium of instruction is English. Written consent from the parents or the guardians of all the learners involved in the research was obtained. The target groups consisted of 35 Grade 1 learners in each of the classes, a total of 70 young learners. The particular learners in the comparison and experimental groups were chosen because they had similar characteristics. The learners who were included in the research project were paired off in the two groups, using the following criteria: age (with reference to the month in which they were born), gender, home language and attendance at a pre-school where English was used as the language of instruction. This entailed distinguishing between learners who were exposed to English and who spoke a little English before entering Grade 1 and those who had not heard or spoken English before - which added to the credibility of the outcome 
of the research. The data did not allow for those learners in the two classes who could not be paired off.

The first step was to examine and select available material to test listening skills, especially phonic skills. All the tests available were, unfortunately, designed for English first-language learners. Evaluation of the ESL learners was therefore done according to the Revised National Curriculum Standards (RNCS) (Department of Education, 2002:16-22) and on a daily basis. The research was aimed at enhancing listening skills through concentration and musical activities. Because of practical restrictions, the learners all came from the same school, and non-probabilistic convenience sampling was used. Convenience sampling is carried out with a group of individuals selected on the basis of simplicity of access and convenience. According to McMillan and Schumacher (2001:175), the primary purpose of research is not to generalise but to gain a better understanding of relationships that may exist.

A number of factors may influence an ESL learner's ability to master English when entering school and these were kept in mind. Examples are the impact of pre-school attendance, especially if English was spoken at the pre-school, and the impact of the socio-economic status of the parents. When the learners were paired off, pre-school attendance and the use of English in the pre-school were among the main variables that were considered. Most of the learners in the school from which the two Grade 1 classes were drawn come from poor socioeconomic circumstances and many learners live with their grandparents. These and other factors will obviously have to be considered when more research based on the positive results obtained from the experimental group is conducted.

It should be mentioned that one variable that could not be controlled was the teachers. The learners in the two classes did not have the same teacher. However, all the Grade 1 classes in this particular school follow the same weekly programme, which is designed by all the Grade 1 teachers, as a group. The experimental group received the music programme in addition to the normal programme because it did not form part of the planned daily activities for all the Grade 1 learners in the school.

A pre-test was conducted with both the experimental group and the control group. After six months, a post-test containing the same type of sub-tests was conducted with the two groups. Each sub-test included a number of items. The tests were conducted individually. Both the pre-test and the post-test contained the following sub-tests:

Sub-test 1: Pitch discrimination. The learners listened to familiar recorded sounds and had to indicate which sounds had a high pitch and which had a low pitch.

Sub-test 2: Dynamics. The learners had to state which part of a piece of music was loud and which part was soft.

Sub-test 3: Auditory discrimination and sequencing. Learners had to identify the location of a particular sound in a spoken word and indicate if it was at the beginning, in the middle or at the end of a word. These activities helped to enhance phonological awareness.

Sub-test 4: Phoneme segmentation and order of sounds. The learners had to identify and state the order of sounds in a word. 
Sub-tests 3 and 4 developed, and at the same time relied strongly on, good auditory perceptual skills and phonological awareness.

During the research period, planned music activities were incorporated into the daily programme of the experimental group, which was in one class, but as stated, it was not part of the daily planned programme for all the Grade 1 learners in the school. The aim was to investigate how the use of music would enhance listening to, and eventually learning through, English as a second language. After six months of extra music activities, the post-test was done with all the learners in both the comparison and the experimental groups. The comparison group did not attend music classes during this period.

Various types of music were used during the research period, ranging from classical music to folk music. Traditional songs were incorporated and also typical African music and songs. The African songs were translated into English. The daily additional music programme of the experimental group of learners included the following:

- Sounds from various instruments were used as pre-language skills. Musical instruments were used to enhance learners' awareness of sequence, loud and soft, fast and slow, high and low and timbre. This helped learners to concentrate and to discriminate more efficiently between different sounds and to improve in their auditory sequencing and auditory discrimination. It also enhanced phonological awareness. Phonological awareness is a very subtle ability to hear similarities and differences between sounds, which are important in home language acquisition and even more important when it comes to the sounds of a new language (Madaule, 2001: 12).

- Songs that helped the young ESL learners to become aware of the soft and loud sounds in the English language were used. According to Rost (2001: 7-13), ESL learners often find it difficult to listen to English because the phonological system, phonotactic rules and tone melodies such as high, low and rising tones may differ from those of their home languages.

- Songs also alerted learners to fast, slow and medium tempos that helped them to become aware of the tempo at which English is spoken. In addition, the songs introduced the learners to common everyday words and idiomatic expressions.

- For auditory awareness, rhythmic speech patterns and rhythm patterns with names were sung. The Orff method was incorporated for rhythmic patterns and the learners discovered how to walk slowly, at a pace, or to run in time to various note values. For instance, the names of learners were used as rhythmic note-value patterns (Grobler, 1990:65).

- The rhythm found in music was also used for movements during the music activities. These included dancing, clapping hands and stamping feet. Movement is more important to learning - including language learning - than has been realised by researchers in the past (Palmer, 2001:13). 


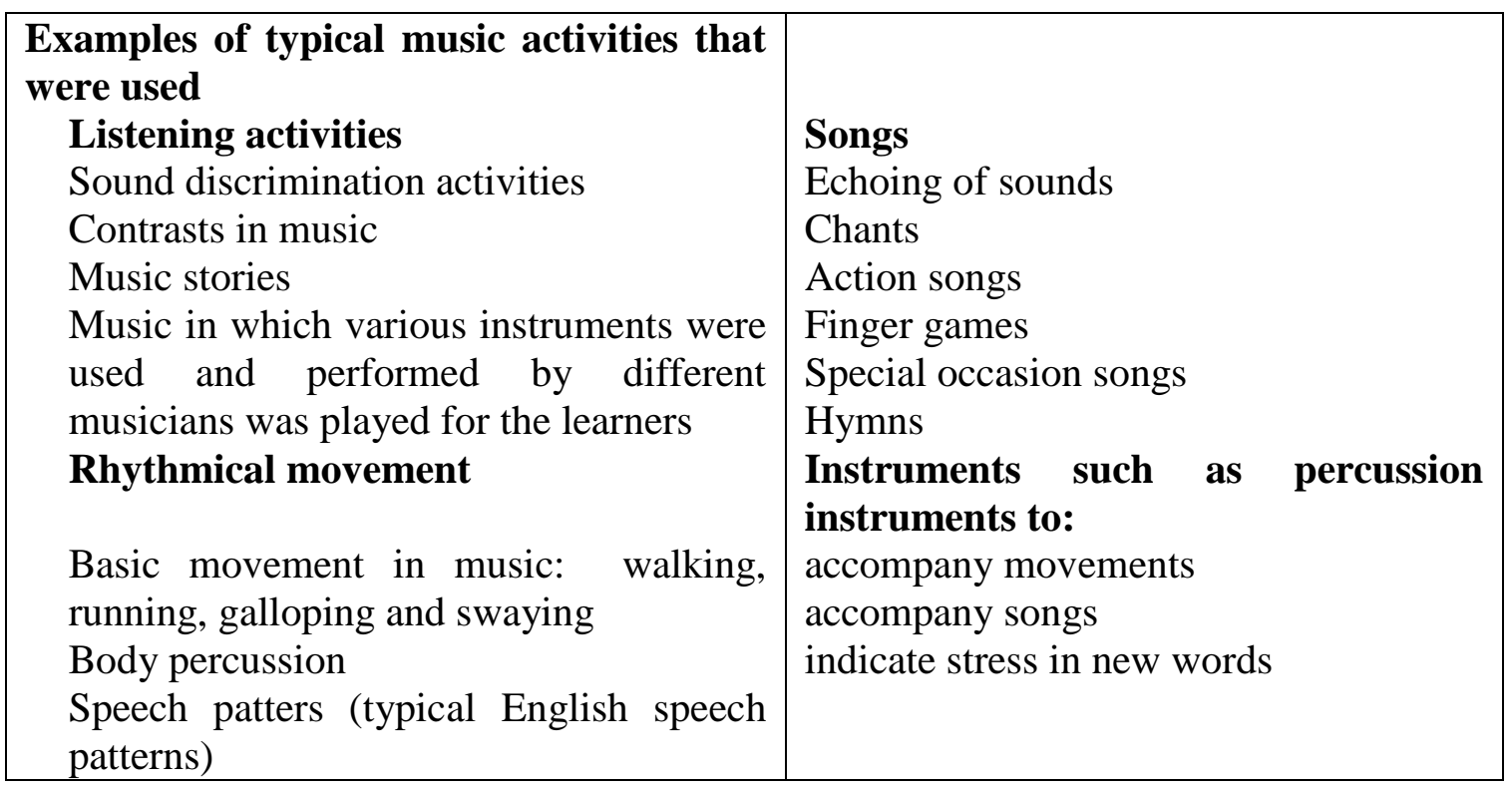

After six months, tests containing the same types of sub-tests were conducted individually with all the learners in the experimental and control groups. By calculating differences between pre-test and post-test marks, information contained in the two separate sets of test results was collated in a single set, indicating improvement or no improvement for each learner. This will not be discussed in this article since it was regarded as of exclusive value to the teachers of the two classes. The music programme used in this research should be seen as a whole and not as consisting of various subsections. The main reason for this is that it is impossible to say whether, for instance, basic sound discrimination or possibly songs could influence the development of listening skills more than other music activities used in the programme. Hence, the researchers deemed it unnecessary to distinguish between the results of each subsection. An overall mean for the entire sample was calculated, and the means for the experimental group and comparison or control group showed the following results.

Table 1: Listening skills: Means for experimental and control group

\begin{tabular}{|c|c|c|c|c|c|c|c|c|}
\hline & $\mathbf{N}$ & Variable & Label & $\mathbf{N}$ & Mean & $\begin{array}{l}\text { Standard } \\
\text { Deviation }\end{array}$ & $\begin{array}{l}\text { Mini- } \\
\text { mum }\end{array}$ & $\begin{array}{l}\text { Maxi- } \\
\text { mum }\end{array}$ \\
\hline $\begin{array}{l}\text { Experi- } \\
\text { mental } \\
\text { group }\end{array}$ & 35 & $\begin{array}{l}\text { Pre-listen } \\
\text { post-listen }\end{array}$ & $\begin{array}{l}\text { Pre-test } \quad \& \\
\text { post-test, } \\
\text { listening skills } \\
\text { difference: } \\
\text { listening }\end{array}$ & $\begin{array}{l}35 \\
35 \\
\\
35\end{array}$ & $\begin{array}{l}25.43 \\
57.54\end{array}$ & $\begin{array}{l}26.69 \\
17.21\end{array}$ & $\begin{array}{r}0.00 \\
20.00\end{array}$ & $\begin{array}{r}100.00 \\
95.00\end{array}$ \\
\hline $\begin{array}{l}\text { Control } \\
\text { group }\end{array}$ & 35 & $\begin{array}{l}\text { Pre-listen } \\
\text { post-listen }\end{array}$ & $\begin{array}{l}\text { Pre-test } \quad \& \\
\text { post-test, } \\
\text { listening skills } \\
\text { difference: } \\
\text { listening }\end{array}$ & $\begin{array}{l}35 \\
35 \\
\\
35\end{array}$ & $\begin{array}{l}27.00 \\
37.26\end{array}$ & $\begin{array}{l}26.44 \\
19.60\end{array}$ & $\begin{array}{r}0.00 \\
10.00\end{array}$ & $\begin{array}{l}90.00 \\
75.00\end{array}$ \\
\hline
\end{tabular}


Multiple comparisons of means were conducted on the difference-means of the various levels of the identified significant variables. Fisher's least significant $t$-test was administered.

Table 2: Difference between pre-tests and post-tests: Fischer's least significance $t$-test Listening skills

\begin{tabular}{|l|l|}
\hline Experimental group & 31.222 \\
\hline Control group & 10.257 \\
\hline
\end{tabular}

Significant differences in means between the experimental and control groups were established for the listening skills in English as a second language. Bearing in mind that the analyses were conducted on the differences between pre-test and post-test marks, the magnitude of the difference-means indicates that the experimental group improved significantly, markedly more than the control group. The experimental group's differencemeans were greater than those of the control group in every instance -31.22 compared to 10.557 for the listening skills - an average improvement of 30 marks in the case of the experimental group as opposed to an average improvement of 10.557 marks for the control group. Music intervention could thus have a positive influence on ESL acquisition and specifically on listening skills in English as a second language. If the acquisition of English by young non-English speaking learners could be enhanced, it would help them to master the language of learning and teaching better. This could help them to make a success of their school career.

\section{CONCLUSION}

The knowledge gained from this research, although it was done on a small scale, could be used in any Foundation Phase classroom. Thus, these quantitative research results could be used practically. Music plays an important role in the curriculum of young learners. Musical activities such as the use of various instruments to enhance learners' awareness of loud and soft, fast and slow, high and low and timbre could be employed. Songs could help to make learners aware of a fast, slow and medium tempo of spoken English and the learners will learn new words and idiomatic expressions from the songs. The Orff method could be included to help learners with rhythm and rhythmical movements. Dancing, clapping of hands and stamping of feet could also be included to enhance learning and language learning. Based on the activities that were used successfully during the research, we concluded that Foundation Phase teachers could use various musical activities to enhance their learners' listening skills in both a first and second language.

Music could eventually be used to help young learners understand English as their second language and language of instruction. One of the main reasons for using music is the fact that listening forms part of every musical activity. Listening is an important component of teaching because it is estimated that $45 \%$ of class time is taken up by listening, meaning that it is used more than any other language skill to obtain knowledge and information (Joubert, Bester \& Meyer, 2007:30). When young learners' listening abilities improve, their other 
language skills in a first or a second language could be strengthened - in addition to their general learning in the classroom.

Songs can play an important role in the acquisition of a new language. For instance, listening to songs could help learners acquire new vocabulary because vocabulary acquisition forms the core of any language learning in both a first and a second language. Carter (2001:47) claims that vocabulary teaching and learning is central to the theory and practice of language teaching. However, songs could also be used for second-language learners to listen to various forms of the spoken language such as idioms and syntax. If CDs and DVDs with songs in English are well selected for ESL teaching, they can introduce the learners to good enunciation and correct pronunciation. Songs are useful for introducing learners to the rhythm of and the relationship between the basic speech sounds of English as their second language.

Music and communication in language both rely on persons' auditory and visual modalities. (Musacchia, Sams, Skoe, \& Kraus, 2007:15894), and as discussed, both modalities are important for second language acquisition. The reason is that lip and facial movements provide timing and segmentation to produce, for instance, vowels and consonants. Similarly, face and body movements convey cues for time-varying features of music such as rhythm and phrasing. The fact that the segmentation that a child has to use when producing vowels and consonants in a second language can be enhanced by music activities is an aspect that all teachers teaching ESL learners should be aware of. The factors that influence word-reading skills in a second language include phonemic awareness, phonics, letter knowledge and a working memory. The process of acquiring sight words is more challenging to secondlanguage readers, and relates to how familiar the readers are with the vocabulary, syntax and phonology of the second language (Helma \& Burns, 2008:15). These requirements could be taught to learners by means of music and songs.

The recommendation is that student teachers should be specially trained in music to equip them to use this valuable means of enhancing the language skills of their learners, especially their ESL learners. Once learners have mastered a nursery song, the words and content of the song could be used creatively, for example, to enhance vocabulary learning and phonological awareness (Sonderman \& Farrell, 2008:38, 63). The link between music and language learning could be used to teach the syllable patterns in words by clapping or tapping.

This research was done on a small scale, but it could open the way to more research using bigger samples. Well-organised and well-planned music programmes could be used country wide because the researchers are of the opinion that music activities could provide a valuable means of helping teachers enhance their learners' - and especially ESL learners' - general language and listening skills. Thus some of the language needs of the young ESL learners in South African classrooms could be addressed.

\section{REFERENCES}

ALIDOU, H, A BOLY, B BROCK-UTNE, YS DIALLO, K HEUGH \& HE WOLFF. 2006. Optimizing learning and education in Africa - the language factor. Association for the Development of Education in Africa (ADEA).

CARTER, R. 2001.Vocabulary. In Carter, R \& D Nunan (Eds), Teaching English to speakers of other languages. Cambridge, UK: Cambridge University Press. 
DEPARTMENT OF EDUCATION. 1997. Language in education policy. Pretoria, RSA: Department of Education.

DEPARTMENT OF EDUCATION. 2002. Revised national curriculum statement Grade R-9. (Schools) policy overview-English. Pretoria, RSA: Department of Education.

DE VOS, AS, H STRYDOM, CB FOUCHÉ \& CSL DELPORT. 2005. Research at grass roots. Pretoria, RSA: Van Schaik.

DE WET, C. 2002. Factors influencing the choice of English as a language of learning and teaching (LoLT). South African Journal of Education. 22(2):119-124.

DIAZ-RICO, LT. 2008. A course for teaching English learners. Boston, MA: Pearson.

DIMITROV, DM. \& D RUMRILL. 2003. Pretest-posttest designs and measurement of change. Work 20:159-165.

ELOFF, I \& L EBERSÖHN. 2004. Keys to educational psychology. Cape Town, RSA: UCT Press.

FLEISCH, B. 2008. Primary education in crisis. Why South African schoolchildren underachieve in reading and mathematics. Cape Town, RSA: JUTA.

GORDON, T. 2007. Teaching young children a second language. Westport, CT,: Praeger.

GROBLER, R. 1990. Musiek in die pre-primêre skool. Durban. RSA: Butterworth.

HALLAM, S. 2001. Learning in music: Complexity and diversity. In Philpott, A \& C Plummeridge (Eds.). Issues in music, pp. 61-66. London, UK: Routlege-Falmer:.

HELMA, LA \& MK BURNS. 2008. What does oral language have to do with it? Helping young English-language learners acquire a sight word vocabulary. The Reading Teacher. 62(4):14-19.

HERRINGTON, J \& R OLIVER. 2000. An instructional design framework for authentic learning environments. Educational Technology Research and Development, 48(3): 2348.

HUGO, A. 2013. Theories and methods of teaching English as a first additional language. In Hugo, A \& E Lenyai (Eds) 2013. Teaching English as a First Additional Language in the Foundation Phase. Pretoria: Van Schaik.

JOUBERT, I, M BESTER, \& E MEYER. 2008. Literacy in the foundation phase. Pretoria, RSA: Van Schaik.

KOURI, T \& K TELANDER. 2008. Children's reading comprehension and narrative recall in sung and spoken story context. Child Language Teaching and Therapy. 24(3):329-249.

KRAUS, N \& B CHANDRASEKARAN. 2010. Music training for the development of auditory skills. Perspectives. 11:599-604. 
KROUSE, MA. 1988. Beginning English: Mastering second language first three years. Babelegi, RSA: Unibook.

MADAULE, P. 2001. Listening, training and music education. South African Music Teacher. 138:10-13.

McMILLAN, JH \& S SCHUMACHER. 2001. Research in education. London, UK: Addison Wesley Longman.

MERDINGER, P \& J ROSENFELD. 1984. Even if you can't carry a tune. Boston: Heinle \& Heinle.

MUSACHIA, G, M SAMS, E SKOE \& N KRAUS. 2007. Musicians have enhanced subcortical auditory and audiovisual processing of speech and music. PNAS. 104(40): 1589-15898.

PALMER, H. 2001. The music, movement and learning connection. Young children, 56(5): 13-17.

PARLIAMENTARY MONITORING GROUP, 2006. Education portfolio committee. Language in education policy: Briefing by department. Available at http://www.pmg.org.za/node/8182

PECA, K. 2000. Positivism in education: philosophical, research and organizational assumptions. U.S. Department of Education Educational Resources Information Centre: $1-33$.

ROST, M. 2001. Listening. In Carter, R \& D Nunan (Eds). Teaching English to speakers of other languages. Cambridge, UK: Cambridge University Press.

SALMON, A. 2010. Using music to promote children's thinking and enhance their literacy development. Early Childhood Development and Care, 180(7):937-945.

SCHEEPERS, R. 2006. The effects of immersion on Grade 7 learners' vocabulary size: Is incidental learning of vocabulary enough? Journal for Language Teaching, 40(2):1-19.

SONDERMAN, A \& P FARRELL. 2008. Creating literacy-rich preschools and kindergartens. Boston: Pearson.

VAN DEVENTER, CS. 1998. Musiek in die ondersteuning van leergestremde leerders in die intermediêre skoolfase in ' $n$ inklusiewe leer omgewing. Unpublished MEd dissertation, University of South Africa, Pretoria, RSA.

WESSELS, M. \& R VAN DEN BERG. 1998. Practical guide to facilitate language learning. Johannesburg, RSA: International Thomson.

\section{BIOGRAPHIC NOTE}

Anna Hugo is a professor in the Department of Language Education, Arts and Culture at the University of South Africa. Her fields of interest are the Teaching of Language and Inclusive Education. Catharina Horn was a postgraduate student at the University of South Africa.

E-mail: hugoaj@unisa.ac.za 